\title{
Adopting Advance Directives Reinforces Patient Participation in End-of-Life Care Discussion
}

\author{
Ji Hyung Hong, MD ${ }^{1,2}$ \\ Jung Hye Kwon, MD, $P h D^{3}$ \\ II Kyu Kim, MD2,4 \\ Jin Hee Ko, RN2 \\ Yi-Jin Kang, RN2 \\ Hoon-Kyo Kim, MD, PhD24
}

\section{${ }^{1}$ Department of Internal Medicine, Incheon St. Mary's Hospital, \\ College of Medicine, \\ The Catholic University of Korea, Incheon, \\ ${ }^{2}$ St. Vincent's Hospital Hospice Center, College of Medicine, \\ The Catholic University of Korea, Suwon, \\ ${ }^{3}$ Division of Hemato-oncology, \\ Department of Internal Medicine, \\ Hallym Universit Kangdong Sacred Heart \\ Hospital, Hallym University \\ College of Medicine, Seoul, \\ ${ }^{4}$ Department of Internal Medicine, \\ St. Vincent's Hospital, College of Medicine, \\ The Catholic University of Korea, Suwon, \\ Korea}

Correspondence: Hoon-Kyo Kim, MD, PhD

Department of Internal Medicine,

St. Vincent's Hospital, College of Medicine,

The Catholic University of Korea,

93 Jungbu-daero, Paldal-gu, Suwon 16247, Korea

Tel: 82-31-249-7127

Fax: 82-31-255-8203

E-mail: miongsok@catholic.ac.kr

Received July 27, 2015

Accepted September 10, 2015

Published Online October 14, 2015

*Ji Hyung Hong and Jung Hye Kwon contributed equally to this work.

\section{Purpose}

In Korea, most terminal cancer patients have still not been included in end-of-life (EOL) discussions. The purpose of this study was to evaluate the proportion of patients participating in EOL discussions after adopting advance directives.

\section{Materials and Methods}

Medical records of 106 hospice patients between July 2012 and February 2013 were reviewed retrospectively. The proportion of patient participation in EOL discussions, barriers, and favorable factors for completion of advance directives, as well as outcomes of advance directives were evaluated.

\section{Results}

Patient participation in EOL discussion had increased from 16/53 (30\%) to 27/53 (51\%) since adopting advance directives $(p<0.001)$. Median time between completion of an advance directive and death increased from 8 days (range, 0 to 22 days) to 14.5 days (range, 0 to 47 days). Patients' poor condition after late referral was the main barrier to missing EOL discussions; however, family members' concerns about patient's distress was also a main reason for excluding the patient from EOL discussions. In univariate analysis, patient age, education status, and time from diagnosis to completion of an advance directive influenced advance directive completion favorably. Following multivariate analysis, higher education and periods of more than 2 years from diagnosis to completion of an advance directive remained favorable (odds ratio [OR], 9.586, $p=0.024$ and $\mathrm{OR}, 70.312 ; \mathrm{p}=0.002$ ). Preferences of all patients regarding cardiopulmonary resuscitation or hemodialysis were carried out by physicians. Orders for nutrition and palliative sedation showed discordance, with concordance rates of $74.2 \%$ and $51.6 \%$, respectively.

\section{Conclusion}

Our results suggested that the use of advance directive promote patient participation in EOL discussion.

\section{Introduction}

Unlike patients dying of acute disease, terminal cancer patients experience end-of-life (EOL) issues as part of their

\section{Key words}

Advance directives, Personal autonomy, Decision making 
Reasons for missing EOL discussions include insufficient time, no guiding materials for medical staff regarding EOL issues, limited knowledge, no medical staff awareness of EOL issues, legal ineffectiveness of advance decision making, and cultural barriers [2-4]. Lack of awareness of the patient's right to EOL care is a major barrier in South Korea and results in continued implementation of ineffective aggressive cancer treatment prior to the EOL period [5-7]. Documentation of advance directives, which express patients' preferences for EOL care, facilitates patient autonomy in EOL discussions and decision making [3].

Between 2003 and 2012, do-not-resuscitate (DNR) forms were used in EOL discussions upon admission to St. Vincent's Hospital Hospice Center. Previous South Korean studies reported that $57 \%$ to $86.7 \%$ of deceased patients from oncology clinics and hospice and palliative care units signed a DNR form; however, $94 \%-100 \%$ of patients were not involved in DNR discussions [8-12]. Since October 1, 2012, advance directive forms have replaced the DNR permission forms in our hospice center to encourage EOL discussions among patients, family members, and physicians.

This study evaluated the proportion of patients participating in EOL discussions with healthcare professionals subsequent to adopting the advance directive.

\section{Materials and Methods}

A palliative care specialist (physician or nurse) discussed EOL issues with patients and/or proxies upon admission. EOL discussion was defined as discussion of the use of lifesustaining treatments and hospice care at terminal status. EOL discussion could be conducted using the DNR form or the advance directives.

The old DNR form simply explained the futility of life sustaining treatment; however, the new advance directive form includes (1) time of EOL discussion; (2) life-sustaining treatment orders, including cardiac massage, inotropes, defibrillation, mechanical ventilation, artificial nutrition or hydration, and hemodialysis; (3) living wills; and (4) healthcare proxy designations. In contrast to classic advance directives, ours requests the patient's permission for later administration of palliative sedation. At the end of the advance directive form, a space is provided for patients to express their feelings or wishes to family members or healthcare professionals. Patients can elect two healthcare proxies, who should be older than 20 years and considered capable of reflecting the patient's usual values and beliefs. Decisions documented in advance directives take effect when the patient becomes unable to make EOL care decisions. However, patients can discard the advance directives at any time.

The medical records of patients admitted to St. Vincent's Hospital Hospice Center between July 6, 2012 and February 28,2013 were reviewed. Reasons for excluding patients from EOL discussions, time from completion of an advance directive to death, time from advanced cancer diagnosis to completion of an advance directive, and translation of patients' EOL care preferences were acquired. EOL discussion was identified if patients' medical records included documentation of an EOL discussion. Patient participation in EOL discussions was defined as a DNR order signed by the patient, a description of the patient's participation in EOL discussions in the medical record, or advance directives.

\section{Results}

A total of 106 patients were admitted to St. Vincent's Hospital Hospice Center between July 6, 2012 and February 28, 2013. Fifty three DNR orders were signed between July 6 and September 31, 2012 (DNR era) and 53 DNR orders or advance directives signed between October 1, 2012 and February 28, 2013 (advance directive era) (Fig. 1).

At the time of analysis, 26 patients with advance directives and all 53 patients with DNR orders were deceased. The median duration of hospital stay was 16 days (range, 0 to 300 days). The median time between completion of an advance directive and death was longer than for the time between DNR and death (14.5 days; range, 0 to 47 days and 8 days; range, 0 to 22 days). The patients' characteristics are shown in Table 1.

\section{Changes in EOL discussions with patients and barriers to EOL discussions}

Patient participation in EOL discussions increased from $16 / 53(30 \%)$ to $27 / 53(51 \%)$ after adoption of an advance directive for EOL discussions in October 1, 2012 ( $\mathrm{p}<0.001)$ (Fig. 1). According to Anselm et al. [13], barriers to EOL discussions can be divided into provider, patient, family member(s), and systemic barriers. Patients' poor condition after late referral was the main barrier to missing EOL discussions in $17 / 18$ patients; however, family members' concerns about patient's distress was also a reason for excluding the patient from EOL discussions (Table 2).

\section{Factors related to EOL care discussion using advance directives}

In the univariate analysis, patients' age and education sta- 


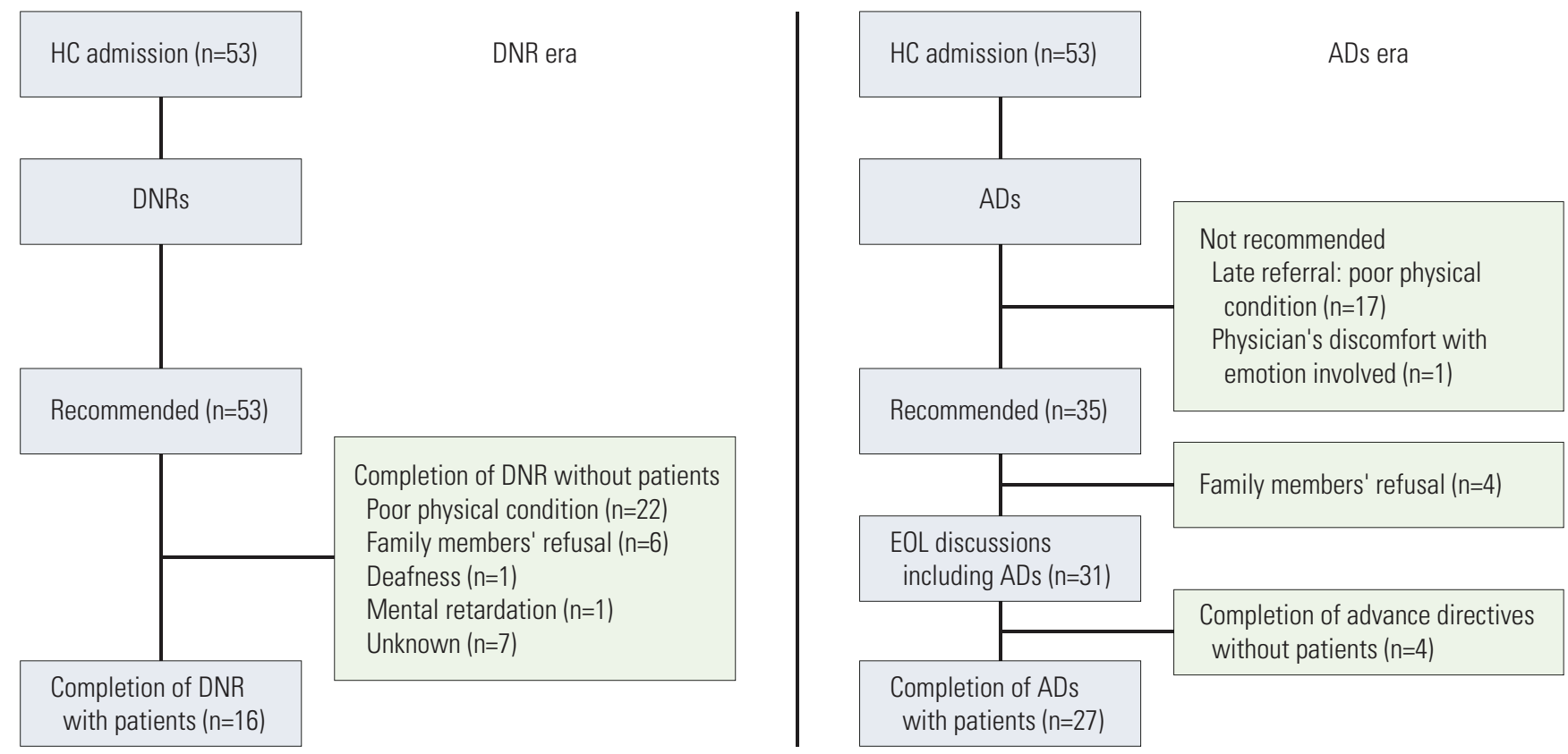

Fig. 1. Study flow. AD, advance directive; DNR, do-not-resuscitate; HC, hospice center; EOL, end-of-life.

Table 1. Patients' characteristics

\begin{tabular}{|c|c|c|c|c|}
\hline Characteristic & Total $(n=106)$ & AD era $(n=53)$ & DNR era $(n=53)$ & p-value \\
\hline \multicolumn{5}{|l|}{ Sex } \\
\hline Male & $58(54.7)$ & $33(62.3)$ & $25: 28$ & 0.172 \\
\hline Age, median (range, yr) & $61(16-85)$ & $61(16-85)$ & $61(39-85)$ & 0.444 \\
\hline \multicolumn{5}{|l|}{ Primary cancer site } \\
\hline Lung & $30(28)$ & $23(43)$ & $7(13)$ & 0.089 \\
\hline Gastrointestinal & $30(28)$ & $9(17)$ & $21(40)$ & \\
\hline Hepatopancreatobiliary & $22(21)$ & $8(15)$ & $14(26)$ & \\
\hline Breast & $6(6)$ & $4(8)$ & $2(4)$ & \\
\hline Other & $18(16)$ & $9(17)$ & $9(17)$ & \\
\hline \multicolumn{5}{|l|}{ Education } \\
\hline$\leq$ Secondary school & $20(19)$ & $7(13)$ & $13(25)$ & 0.550 \\
\hline Middle school & $18(17)$ & $11(21)$ & $7(13)$ & \\
\hline High school & $35(33)$ & $19(36)$ & $16(30)$ & \\
\hline College graduate & $14(13)$ & $9(17)$ & $5(9)$ & \\
\hline Graduate degree & $2(2)$ & $1(2)$ & $1(2)$ & \\
\hline Unavailable & $17(16)$ & $6(11)$ & $11(21)$ & \\
\hline \multicolumn{5}{|l|}{ Religion } \\
\hline Catholic & $24(23)$ & $7(13)$ & $17(32)$ & 0.890 \\
\hline Protestant & $24(23)$ & $11(21)$ & $13(25)$ & \\
\hline Buddhism & $10(10)$ & $3(6)$ & $7(13)$ & \\
\hline Other & $48(45)$ & $32(60)$ & $16(30)$ & \\
\hline
\end{tabular}

Values are presented as number $(\%)$. AD, advance directive; DNR, do not resuscitate. 
Table 2. Barriers to patient participation in EOL discussion in the advance directives era $(n=22)$

\begin{tabular}{|c|c|c|c|}
\hline & $\begin{array}{l}\text { Patient and family member } \\
\text { barrier }\end{array}$ & Provider barrier & Systemic barrier \\
\hline \multirow[t]{2}{*}{$\begin{array}{l}\text { EOL discussion was not } \\
\text { recommended }(\mathrm{n}=18,34 \%)\end{array}$} & - & $\begin{array}{l}\text { Discomfort with } \\
\text { emotion involved }(n=1)\end{array}$ & - \\
\hline & - & - & $\begin{array}{l}\text { Late referral: poor physical } \\
\text { condition when patients were } \\
\text { transferred }(\mathrm{n}=17)\end{array}$ \\
\hline \multirow{3}{*}{$\begin{array}{l}\text { EOL discussion was } \\
\text { recommended and patients } \\
\text { were excluded }(n=4,8 \%)\end{array}$} & $\begin{array}{l}\text { Family's concern about } \\
\text { patient's distress }(n=1)\end{array}$ & - & - \\
\hline & Refusal without any reason $(\mathrm{n}=1)$ & - & - \\
\hline & - & - & $\begin{array}{l}\text { Late referral: poor physical } \\
\text { condition when patients were } \\
\text { transferred }(n=2)\end{array}$ \\
\hline
\end{tabular}

EOL, end-of-life.

Table 3. Factors affecting advance directive completion $(n=53)$

\begin{tabular}{|c|c|c|c|c|}
\hline Factor & Crude odds ratio (95\% CI) & p-value & Adjusted odds ratio ( $95 \% \mathrm{CI})$ & p-value \\
\hline Age ( $>60$ yr vs. $<60$ yr) & 4.894 (1.488-16.097) & $0.009^{*}$ & $2.919(0.617-13.815)$ & 0.177 \\
\hline Sex (female vs. male) & $2.479(0.766-8.028)$ & 0.130 & $2.806(0.462-17.031)$ & 0.262 \\
\hline $\begin{array}{l}\text { Education ( } \geq \text { high school graduate vs. } \\
\leq \text { middle school graduate) }\end{array}$ & $3.630(1.155-11.406)$ & $0.027^{*}$ & $9.586(1.355-67.788)$ & $0.024^{*}$ \\
\hline $\begin{array}{l}\text { Time from diagnosis to completion of } \\
\text { advance directive ( }>2 \mathrm{yr} \text { vs. }<2 \mathrm{yr} \text { ) }\end{array}$ & $22.000(2.620-184.752)$ & $0.004^{*}$ & $70.312(4.745-1041.883)$ & $0.002^{*}$ \\
\hline
\end{tabular}

*Statistically significant.

tus and the time between diagnosis and completion of an advance directive influenced advance directive completion favorably during EOL discussions. Following multivariate analysis, higher education and a period of more than 2 years between diagnosis and advance directive completion remained favorable factors (odds ratio [OR], 9,586; $\mathrm{p}=0.024$ and OR, 70.312; $\mathrm{p}=0.002$ ) (Table 3).

\section{Outcome of advance directives}

All patients who had agreed to completion of an advance directive chose their spouses or immediate family members as healthcare proxies. Patients' preferences and medical orders are detailed in Table 4. Physicians carried out preferences of all patients' regarding cardiopulmonary resuscitation or hemodialysis. Orders for nutrition and palliative sedation showed concordance rates of $74.2 \%$ and $51.6 \%$, respectively.

\section{Discussion}

In this study, adoption of advance directives in EOL discussions increased patient participation. Previous South Korean studies reported that most patients did not participate in EOL discussions when DNR orders were used; however, with use of advance directive, $3.3 \%-4.8 \%$ of patients had written advance directives themselves [8-12]. In a study conducted in the United States, 33\% of patients participated in EOL discussions using DNR [14]; with advance directives, the rate of patient participation in EOL discussions was $50 \%-62 \%[15,16]$. The objective of advance directives for patients is to state their personal preferences in advance, even if legally incompetent [17]. Increased patient participation in EOL discussions could reflect increased patient autonomy in EOL care. Therefore, our study showed that adopting advance directives can increase patient participation in EOL discussions, which could enhance their autonomy. Further study is required to evaluate the relationship 
Table 4. Outcomes of advance directives

\begin{tabular}{|c|c|c|c|c|c|}
\hline Factor & $\begin{array}{c}\text { Documented preference } \\
\text { for EOL }\end{array}$ & No. & $\begin{array}{c}\text { Treatment Received } \\
\text { during EOL }\end{array}$ & No. & Concordance rate \\
\hline \multirow[t]{2}{*}{ Cardiopulmonary resuscitation } & Yes & 0 & Received & 0 & $31 / 31(100)$ \\
\hline & No & 31 & Not received & 31 & \\
\hline \multirow[t]{2}{*}{ Tube feeding/Total parenteral nutrition } & Yes & 9 & Received & 1 & $23 / 31(74.2)$ \\
\hline & No & 22 & Not received & 30 & \\
\hline \multirow[t]{2}{*}{ Renal replacement therapy } & Yes & 0 & Received & 0 & $31 / 31(100)$ \\
\hline & No & 31 & Not received & 31 & \\
\hline \multirow[t]{2}{*}{ Palliative sedation } & Yes & 22 & Received & 7 & $16 / 31(51.6)$ \\
\hline & No & 9 & Not received & 24 & \\
\hline
\end{tabular}

Values are presented as number (\%). EOL, end-of-life.

between participation in EOL discussion and patients' autonomy.

The most common reason that patients did not participate in EOL discussions was poor physical condition, and family members' concern about patients' distress when discussing their poor prognoses and death was another main reason. Poor physical condition after late referral could be classified as a systemic barrier; however, because negative attitudes toward advance directives and poor communication skills in healthcare providers were not recorded in the medical records, the results may be derived from a combination of provider and systemic barriers.

In our study, cardiopulmonary resuscitation and renal replacement were carried out consistent with documented advance directive preferences in all cases. However, some patients' preferences regarding nutrition and palliative sedation were not carried out by a physician as a part of EOL care. According to the medical record and discussion with physicians, patients' previous preference in advance directives regarding nutrional support and palliative sedation turned out to be inapproriate for them at the time of event, thus, the advance directives they had previously selected as preferred were not followed. In a previous study conducted in the United States, medical treatment was consistent with advance directives for $75 \%$ of patients (72/96); in $6.3 \%$ of cases, care was more aggressive than requested and in $18.8 \%$ of cases, it was less aggressive than requested [15]. In another study involving Korean patients with endstage renal disease, some patients who had stated that they did not wish to be resuscitated had died during resuscitation [18]. Even though Physician Orders for Life-Sustaining Treatment were distributed in the United States, there have been difficulties interpreting and fulfilling patients' requests $[19,20]$.

Palliative sedation in case of refractory symptoms was included in our advance directive form. Most advance directive forms do not include palliative sedation $[15,21,22]$. How- ever, in a Swiss study using advance directives in which patients were asked to write down their preferences rather than complete a pre-established checklist, more than $50 \%$ of patients expressed their preferences for palliative sedation in case of refractory symptoms [23]. Of the 76 patients who completed advance directives in our hospice center between October 2012 and September 2013, 89.5\% (68/76) expressed their preferences for palliative sedation in advance directives [24]. Actually, when the patients showed deterioration, a discussion regarding palliative sedation was not generally possible. Therefore, we suggested that the palliative sedation content be included in the list of advance directives.

This research had some limitations. The study was a retrospective review of medical records; therefore, we may not have captured all EOL discussions between physicians and patients. We might have missed patients who were involved in EOL discussions but did not sign the form themselves. In a small number of patients, identification of reliable factors associated with patients' completion of an advance directive was difficult. We assumed that signing advance directives indicated participation in EOL discussion and honored patients' autonomy; however, a prospective observational study is required to clarify this relationship. Further study to evaluate the content of and barriers to EOL discussions is also required.

\section{Conclusion}

In the current study, use of advance directives in EOL discussion increased the rate of participation of advanced cancer patients in EOL discussions. Prospective trials involving large numbers of patients are required to confirm these results. 


\section{Conflicts of Interest}

Conflict of interest relevant to this article was not reported.

\section{References}

1. National Consensus Project for Quality Palliative Care. Clinical practice guidelines for quality palliative care, 3rd ed. [Internet]. Pittsburgh, PA: National Consensus Project for Quality Palliative Care; 2013 [cited 2015 Oct 1]. Available from: http://www.nationalconsensusproject.org/NCP_Clinical_Pra ctice_Guidelines_3rd_Edition.pdf.

2. Heo DS. Patient autonomy and advance directives in Korea. J Korean Med Assoc. 2009;52:865-70.

3. Keam B, Yun YH, Heo DS, Park BW, Cho CH, Kim S, et al. The attitudes of Korean cancer patients, family caregivers, oncologists, and members of the general public toward advance directives. Support Care Cancer. 2013;21:1437-44.

4. Ngo-Metzger Q, McCarthy EP, Burns RB, Davis RB, Li FP, Phillips RS. Older Asian Americans and Pacific Islanders dying of cancer use hospice less frequently than older white patients. Am J Med. 2003;115:47-53.

5. Andreis F, Rizzi A, Rota L, Meriggi F, Mazzocchi M, Zaniboni A. Chemotherapy use at the end of life: a retrospective single centre experience analysis. Tumori. 2011;97:30-4.

6. Hong JH, Rho SY, Hong YS. Trends in the aggressiveness of end-of-life care for advanced stomach cancer patients. Cancer Res Treat. 2013;45:270-5.

7. Keam B, Oh DY, Lee SH, Kim DW, Kim MR, Im SA, et al. Aggressiveness of cancer-care near the end-of-life in Korea. Jpn J Clin Oncol. 2008;38:381-6.

8. Kim DY, Lee KE, Nam EM, Lee HR, Lee KW, Kim JH, et al. Do-not-resuscitate orders for terminal patients with cancer in teaching hospitals of Korea. J Palliat Med. 2007;10:1153-8.

9. Oh DY, Kim JH, Kim DW, Im SA, Kim TY, Heo DS, et al. CPR or DNR? End-of-life decision in Korean cancer patients: a single center's experience. Support Care Cancer. 2006;14:103-8.

10. Shim BY, Hong SI, Park JM, Cho HJ, Ok JS, Kim SY, et al. DNR (Do-Not-Resuscitate) order for terminal cancer patients at hospice ward. Korean J Hosp Palliat Care. 2004;7:232-7.

11. Kwon SH, Im SH, Cho KW, Cho E, Yoon SJ, Oh SY. Most advance directives written by patients with advanced cancer or their proxies request only minimally invasive treatments during end-of-life care. Am J Hosp Palliat Care. 2012;29: 622-6.

12. Park IK, Jun HJ, Park SJ, Lim GJ, Cho SJ, Song A, et al. Differences in end-of-life care decision making between patients with and without cancer. Am J Hosp Palliat Care. 2015;32: 797-801.

13. Anselm AH, Palda V, Guest CB, McLean RF, Vachon ML, Kelner $\mathrm{M}$, et al. Barriers to communication regarding end-of-life care: perspectives of care providers. J Crit Care. 2005;20: 214-23.

14. Weiss GL, Hite CA. The do-not-resuscitate decision: the context, process, and consequences of DNR orders. Death Stud. 2000;24:307-23.

15. Danis M, Southerland LI, Garrett JM, Smith JL, Hielema F, Pickard CG, et al. A prospective study of advance directives for life-sustaining care. N Engl J Med. 1991;324:882-8.

16. Heintz LL. Efficacy of advance directives in a general hospital. Hawaii Med J. 1997;56:203-6.

17. Brown BA. The history of advance directives: a literature review. J Gerontol Nurs. 2003;29:4-14.

18. Nam YH, Seo IS, Lim JH, Choi JH, Kim JE, Choi JH, et al. Application of advance directives for patients with end stage renal disease. Korean J Nephrol. 2008;27:85-93.

19. Schmidt TA, Zive D, Fromme EK, Cook JN, Tolle SW. Physician orders for life-sustaining treatment (POLST): lessons learned from analysis of the Oregon POLST Registry. Resuscitation. 2014;85:480-5.

20. Fromme EK, Zive D, Schmidt TA, Cook JN, Tolle SW. Association between physician orders for life-sustaining treatment for scope of treatment and in-hospital death in Oregon. J Am Geriatr Soc. 2014;62:1246-51.

21. Schneiderman LJ, Kronick R, Kaplan RM, Anderson JP, Langer RD. Effects of offering advance directives on medical treatments and costs. Ann Intern Med. 1992;117:599-606.

22. Reilly BM, Wagner M, Magnussen CR, Ross J, Papa L, Ash J. Promoting inpatient directives about life-sustaining treatments in a community hospital: results of a 3-year time-series intervention trial. Arch Intern Med. 1995;155:2317-23.

23. Pautex S, Notaridis G, Derame L, Zulian GB. Preferences of elderly cancer patients in their advance directives. Crit Rev Oncol Hematol. 2010;74:61-5.

24. Kong BH, An HJ, Kim HS, Ha SY, Kim IK, Lee JE, et al. Experience of advance directives in a hospice center. J Korean Med Sci. 2015;30:151-4. 